\title{
Defective Dopamine-1 Receptor Adenylate Cyclase Coupling in the Proximal Convoluted Tubule from the Spontaneously Hypertensive Rat
}

\author{
Shohei Kinoshita, * Anita Sidhu, and Robin A. Felder* \\ *Department of Pathology, University of Virginia Health Sciences Center, Charlottesville, Virginia 22908, \\ and Membrane Biochemistry Section, Laboratory of Molecular and Cellular Neurobiology, National Institute of Neurological \\ and Communicative Disorders and Stroke, Bethesda, Maryland 20892
}

\begin{abstract}
The natriuretic effect of DA-1 agonists is less in the spontaneously hypertensive rat (SHR) than its normotensive control, the Wistar-Kyoto rat (WKY). To determine a mechanism of the decreased effect of DA-1 agonists on sodium transport, DA-1 receptors in renal proximal convoluted tubule (PCT) were studied by radioligand binding and by adenylate cyclase (AC) determinations. Specific binding of ${ }^{125} \mathrm{I}-\mathrm{SCH} 23982$ (defined by $10 \mu \mathrm{M}$ SCH 23390, a DA-1 antagonist) was concentration dependent, saturable, and stereoselective. The dissociation constant, maximum receptor density, and DA-1 antagonist inhibition constant were similar in SHR and WKY. The apparent molecular weight of the DA-1 receptor determined by the photoaffinity $D_{1}$ probe ${ }^{125}$ I-MAB was also similar in WKY and SHR. However, DA-1 agonists competed more effectively for specific ${ }^{125}$ I-SCH 23982 binding sites in WKY than in SHR. Basal as well as forskolin, parathyroid hormone, GTP and Gpp(NH)p-stimulated-AC activities were similar. In contrast DA-1 agonists (fenoldopam, SKF 38393, SND 911C12) stimulated AC activity to a lesser extent in SHR. GTP and Gpp(NH)p enhanced the ability of DA-1 agonists to stimulate AC activity in WKY but not in SHR. These data suggest a defect in the DA-1 receptor-second messenger coupling mechanism in the PCT of the SHR.
\end{abstract}

\section{Introduction}

It has been suggested that nonneuronal dopamine produced locally in the kidney (1-5) acts as a paracrine or autocrine substance causing an inhibition of sodium transport $(3,5-8$, $8 \mathrm{a})$. The enzymes necessary to synthesize dopamine are found in the kidney (9); aromatic L-amino acid decarboxylase, which converts L-DOPA to dopamine, seems to be mainly located around the apical cell membrane (5) of the S1 and S2 segments of the renal proximal tubule (10). Dopamine produced in the proximal convoluted tubule $(\mathrm{PCT})^{1}(1,5,10,11)$ may inhibit

This work has been previously published in abstract form in 1989 . (Kidney Int. 35: 329.)

Address reprint requests to Dr. Felder, Department of Pathology, Box 168, University of Virginia Health Sciences Center, Charlottesville, VA 22908. 1989.

Received for publication 12 April 1989 and in revised form $10 \mathrm{July}$

J. Clin. Invest.

(c) The American Society for Clinical Investigation, Inc.

$0021-9738 / 89 / 12 / 1849 / 08 \quad \$ 2.00$

Volume 84, December 1989, 1849-1856
$\mathrm{Na}^{+}$transport in part by occupation of the DA-1 receptor $(6-8$, $11,12)$. The dopamine-regulated sodium transport in PCT may be mediated by inhibition of $\mathrm{Na}^{+} / \mathrm{K}^{+}$ATPase $(1,5$, 11-13) and $\mathrm{Na}^{+} / \mathrm{H}^{+}$antiport activities (14). The latter effect may be mediated by stimulation of adenylate cyclase (AC) activity (14). Dopamine and DA-1 agonists may also decrease sodium transport in nephron segments beyond the proximal tubule (15), including the cortical collecting duct (16). We have previously reported the presence of DA-1 receptors coupled to stimulation of adenylate cyclase in the PCT of the rabbit (17) and rat kidney (18). These receptors are also present in proximal straight tubule (17-20) and cortical collecting duct $(16,19)$.

Abnormalities in the renal dopaminergic system have been reported in genetically hypertensive rat including the spontaneously hypertensive rat (SHR) of the Okamoto Aoki strain (21-26). The natriuretic effects of DA-1 agonists $(25,26)$ and the antinatriuretic effects of a DA-1 antagonist (6) are reduced in the SHR. These experiments were therefore designed to determine if there are differences in DA-1 receptor density or affinity and/or AC activity in PCT of SHR and Wistar-Kyoto rat (WKY). The microdissected PCT was chosen because the study of whole renal homogenates may obscure the presence of biochemical defects in specific nephron segments.

\section{Methods}

\section{Dissection of proximal convoluted tubules}

PCT was microdissected from male 18-20-wk-old SHR (mean arterial pressure $166.6 \pm 2.7 \mathrm{mmHg}, n=9$ ) and WKY (mean arterial pressure $111.3 \pm 1.5 \mathrm{mmHg}, n=9$ ) (Harlan-Sprague Dawley, Inc., Indianapolis, IN) according to the procedure previously described from this laboratory $(17,18)$. In a separate group of experiments 3 -wk-old WKY and SHR were used. The rats were maintained on a standard rat chow with ad lib. access to water. After the rats were killed by decapitation, the descending aorta was cannulated with PE-90 polyethylene tubing, and the kidneys were perfused via a peristaltic pump (WIZ; Isco Inc., Lincoln, NE). The perfusate consisted of a calcium-free Dulbecco's PBS, pH 7.4 (Gibco Laboratories, Grand Island, NY) containing collagenase, $200 \mathrm{mg} / \mathrm{dl}$ (Type IV, Sigma C-5831; Sigma Chemical Co., St. Louis, MO) and glucose ( $1 \mathrm{~g} /$ liter $)$, at $25^{\circ} \mathrm{C}$. After perfusing the kidney with the collagenase solution, the cortical tissue was sliced into $0.5-\mathrm{mm}$ sections followed by incubation in calcium-free Dulbecco's buffer, $\mathrm{pH}$ 7.4 , at $37^{\circ} \mathrm{C}$ for $0-15 \mathrm{~min}$. Incubation time varied from lot to lot of collagenase. After two quick rinses with ice-cold Dulbecco's buffer the tissues were transferred into Petri dishes with ice-cold Dulbecco's buffer containing glucose ( $1 \mathrm{~g} /$ liter), $200 \mu \mathrm{M}$ vitamin $\mathrm{E}$ (Trolox 06718JM; Aldrich Chemical Co., Milwaukee, WI) and $1 \mathrm{mM}$ ascorbic acid (A-0278; Sigma Chemical Co.). Dissection was performed at $4^{\circ} \mathrm{C}$

1. Abbreviations used in this paper: $\mathrm{AC}$, adenylate cyclase; $\mathrm{PCT}$, proximal convoluted tubule; SHR, spontaneously hypertensive rat; WKY, Wistar-Kyoto rat. 
under a Wild stereozoom microscope with dark-field illumination as previously described (17). PCT (S1 and S2) was microdissected manually. The PCT was identified by an attached glomerulus and its location in the renal labyrinth and milky appearance (27).

\section{Quantitative autoradiographic studies of microdissected nephrons}

After microdissection, the tubules were transferred in $5 \mu \mathrm{l}$ of microdissection solution (Dulbecco's buffer without collagenase) onto cold glass slides (teflon-coated microscope slides, Cel-Line Associates Inc., Newfield, NJ) for autoradiographic studies. The glass slides were prepared for binding studies by cleaning with $1 \%$ hydrochloric acid followed by dipping in deionized $\mathrm{H}_{2} \mathrm{O}$. The glass slides were coated with $0.1 \%$ (wt/vol in water) poly-D-lysine hydrobromide (Sigma P-1524). The nephron segments were air dried on the poly-D-lysine coated slides and stored frozen with desiccant at $-80^{\circ} \mathrm{C}$ for at least $24 \mathrm{~h}$. Tubular length was measured with a reticle attachment to the stereomicroscope. All tubular length measurements are reported in unstretched lengths. We found greater reproducibility in PCT measurement using unstretched length as compared to stretched length when length was correlated with protein content determined by the method of Lowry et al. (28) $(r=0.98$ unstretched vs. protein content, $r=0.82$ stretched vs. protein content).

Saturation studies. Desiccated tubules were preincubated for $5 \mathrm{~min}$ in a calcium-free Dulbecco's PBS (pH 7.4) containing glucose $(1 \mathrm{~g} /$ liter), at room temperature. The tubules were then incubated in the same buffer with varying concentrations of ${ }^{125} \mathrm{I}-\mathrm{SCH}-23982$ (New England Nuclear, Boston, MA) ranging from 3.25 to $50 \mathrm{nM}$. This concentration range was previously found to be optimal for DA-1 receptors in the rat renal cortex (29). Nonspecific binding was determined by incubation under the same conditions with the addition of $10 \mu \mathrm{M}$ SCH-23390 (a selective DA-1 antagonist; Schering Corp., Kenilworth, $\mathrm{NJ})$. After $30 \mathrm{~min}$ incubation, the tubules were washed with ice-cold buffer three times and dried under a stream of room temperature air. Since SCH-23390 has been shown to bind to serotonin $5 \mathrm{HT}_{1 \mathrm{c}}$ and other receptors in tissues other than the kidney, the validity of the definition of specific binding in the kidney was verified by additivity studies. Prazosin $(10 \mu \mathrm{M})$, an alpha $\mathrm{a}_{1}$ adrenergic antagonist, and pindolol $(10 \mu \mathrm{M})$, a beta adrenergic antagonist that also blocks serotonin receptors did not decrease further the specific binding indicating that ${ }^{125} \mathrm{I}-\mathrm{SCH}-23982$ was not binding to a proximal tubular serotonin $5 \mathrm{HT}_{1}$, alpha or beta adrenergic receptor. We have previously reported that in the kidney, ketanserin, a serotonin $5 \mathrm{HT}_{2}$ antagonist did not compete effectively for specific ${ }^{125} \mathrm{I}-\mathrm{SCH}-23982$ three binding sites (29). Moreover, the addition of $10 \mu \mathrm{M}$ serotonin did not cause additional displacement of ${ }^{125} \mathrm{I}-\mathrm{SCH}-23982$ binding.

Competition studies. The ability of various drugs to compete for specific ${ }^{125} \mathrm{I}-\mathrm{SCH}-23982$ binding sites in microdissected PCT was determined. The DA-1 antagonists used were SCH-23390 and SCH-23388 (nonactive enantiomer of SCH-23390) and the agonists used were fenoldopam, SKF-38393, and the novel noncatechol DA-1 agonist SND-919C12 $(18,30)$ (Felder, R. A., unpublished observations). The tubules and ${ }^{14} \mathrm{C}$ standards were exposed to ultrafilm (LKB, Uppsala, Sweden) for 24-72 h. After development, autoradiographic density was quantitated using microdensitometry (Leitz Orthergolux; Bunton Instruments, Rockville, MD). Density units were converted to radioactive decay units and subsequently to drug concentrations by comparing to known densities determined from microscales included in each autoradiographic exposure as previously described (29).

Adenylate cyclase $(A C)$ studies. For quantitation of AC activity, 3-mm segments of PCT were permeabilized by exposing the segments to $20 \mu \mathrm{l}$ of hypotonic medium (1.5 $\mu \mathrm{l}$ of calcium-free Dulbecco's PBS with glucose, $1 \mathrm{~g} /$ liter and $18.5 \mu \mathrm{l}$ of distilled $\mathrm{H}_{2} \mathrm{O}$ ) for $20 \mathrm{~min}$ and then by freezing and thawing before determination of $\mathrm{AC}$ activity $(17,18)$. Cyclic AMP was generated and subsequently measured by radioimmunoassay as previously described from our laboratory (17). The PCT was permeabilized by exposing dissected PCT to $20 \mu \mathrm{l}$ of hypotonic medium and freezing on dry ice. A calcium-free Dulbecco's PBS buffer was then added ( $60 \mu \mathrm{l}, \mathrm{pH} 7.4)$ containing $16.2 \mathrm{mM} \mathrm{MgCl}, 540 \mu \mathrm{M}$ IBMX, $600 \mu \mathrm{M}$ EGTA, $0.25 \mathrm{mM}$ ATP, and $0.01 \mathrm{mM}$ GTP (final concentration). An ATP regenerating system was not used in these experiments. We previously found a linear production of cAMP over a 30-min incubation time with and without an ATP regenerating system $(17,18)$. Deionized water $(20 \mu \mathrm{l})$, with and without various drugs to be tested were added to each tube. The reaction was started by placing the tubes in a $37^{\circ} \mathrm{C}$ shaking water bath for $20 \mathrm{~min}$. The incubation was terminated by boiling the tubes for $5 \mathrm{~min}$. Ice-cold sodium acetate buffer ( $400 \mu$ l, $5 \mathrm{mM}, \mathrm{pH} 4.75)$ was added to each tube. Thereafter, 50 $\mu \mathrm{l}$ of the samples were added to $200 \mu \mathrm{l}$ of antibody solution $(10 \mu \mathrm{l}$ of antibody brought up to $500 \mathrm{ml}$ of $50 \mathrm{mM}$ sodium acetate with $5 \mathrm{mg} / \mathrm{ml}$ BSA). Trace ${ }^{125} \mathrm{I}$-cAMP $(50 \mu \mathrm{l}=10,000 \mathrm{cpm})$ was added to each tube and then the tubes were incubated for $12-24 \mathrm{~h}$ at $4^{\circ} \mathrm{C} .700 \mu \mathrm{l}$ of Staphylococcus aureus (Staphylococcus aureus solution: $50 \mathrm{mM}$ sodium acetate; 1:11 vol/vol, Sigma catalogue S-2014) was added to each tube. After $1 \mathrm{~h}$ incubation, the tubes were centrifuged at 3,000 rpm for $10 \mathrm{~min}$ and the gamma emissions in the precipitates were measured in a gamma counter. The antagonists used in these studies were the DA-1 antagonist SCH-23390, and beta adrenergic antagonist (-)-propranolol. The selective DA-1 agonists used were fenoldopam, SKF-38393, and SND-919-C12.

\section{Photoaffinity labeling of the DA-1 receptor}

Microdissected PCT were labeled with the D-1 dopamine specific photoaffinity probe, ${ }^{125} \mathrm{I}-\mathrm{MAB}$, with modification of the previously described procedure (31). $2 \mathrm{~cm}$ of PCT from both the WKY and SHR were suspended in two separate tubes $(1 \mathrm{~cm}$ each) in $1.0 \mathrm{ml}$ assay buffer ( $25 \mathrm{mM}$ Tris- $\mathrm{HCl}, 100 \mathrm{mM} \mathrm{NaCl}, \mathrm{pH} \mathrm{7.4}$, and the following protease inhibitors: $1 \mathrm{mM}$ EDTA, $0.5 \mathrm{mM}$ PMSF, $5 \mu \mathrm{g} / \mathrm{ml}$ leupeptin, and 5 $\mu \mathrm{g} / \mathrm{ml}$ pepstatin). The PCT suspensions were incubated in the dark for $90 \mathrm{~min}$ at $25^{\circ} \mathrm{C}$ in the presence or absence SCH-23390 $(10 \mu \mathrm{M})$ to determine nonspecific binding or total binding, respectively. After incubation the samples were centrifuged at $15,000 \mathrm{~g}\left(20 \mathrm{~min}, 4^{\circ} \mathrm{C}\right)$. The pellets were then washed with $1.2 \mathrm{ml}$ of buffer $(25 \mathrm{mM}$ Tris- $\mathrm{HCl}, \mathrm{pH}$ $7.4,100 \mathrm{mM} \mathrm{NaCl}$, protease inhibitors and $0.5 \% \mathrm{BSA}$ ) and then recentrifuged. The pellets were resuspended in $0.2 \mathrm{ml}$ of the Tris buffer (without BSA) and illuminated with ultraviolet light from a hand-held (model ENF 28; Spectronics Corp.) ultraviolet lamp (254 nm) for $35 \mathrm{~s}$ at $4^{\circ} \mathrm{C}$. The samples were then diluted with $1 \mathrm{ml}$ of $25 \mathrm{mM}$ Tris buffer (without BSA), recentrifuged, and prepared for SDS-PAGE as described below.

The photoaffinity labeled PCT samples were washed once with 25 $\mathrm{mM}$ Tris buffer and suspended in $100 \mu \mathrm{l}$ of SDS-PAGE buffer $(25 \mathrm{mM}$ Tris- $\mathrm{HCl}, \mathrm{pH} 6.8,10 \%$ SDS, $10 \%$ glycerol, and 5\% beta-mercaptoethanol with proteolytic enzyme inhibitors). After an overnight incubation at $22^{\circ} \mathrm{C}$, the SDS-solubilized samples were subjected to electrophoresis on polyacrylamide slab gels; a $4.5 \%$ upper stacking gel and $10 \%$ separating gel were used. After completion of the electrophoresis, the gel was dried using a slab gel drier (model 224; Bio-Rad Laboratories, Richmond, CA) and autoradiographed at $-80^{\circ} \mathrm{C}$ with Kodak XAR-5 film.

Statistical analyses. The results are expressed as mean $\pm \mathrm{SE}$. The dissociation constant $\left(K_{\mathrm{d}}\right)$, maximum receptor density $\left(B_{\max }\right)$, and inhibition constants $\left(K_{\mathrm{i}}\right)$ were calculated using nonlinear regression (Lundon 1,2; Lundon Software, Inc., Cleveland, $\mathrm{OH}$ ). Significant differences $(P<0.05)$ were determined using a paired $t$ test when two groups were compared and ANOVA for repeated measures, Scheffe's test was used when more than two groups were compared.

\section{Results}

\section{Radioligand binding studies}

Saturation studies. The specific binding of ${ }^{125} \mathrm{I}-\mathrm{SCH} 23982$ reached steady state in the rat PCT after $30 \mathrm{~min}$ (data not shown). Scatchard plots were linear, similar to our previous 
findings $(18,29)$ (Fig. 1). Specific binding $\left(55 \%\right.$ at $\left.K_{\mathrm{d}}\right)$ of ${ }^{125} \mathrm{I}$ SCH-23982 to rat PCT was concentration dependent and saturable in both WKY and SHR (Fig. 1, insets). The $K_{\mathrm{d}}$ and $B_{\max }$ were not different between the SHR and WKY. $K_{\mathrm{d}}$ was $10.9 \pm 1.3 \mathrm{nM}, 10.7 \pm 0.9 \mathrm{nM}$ and $B_{\max }$ was $479.1 \pm 22.2$, $601.0 \pm 91.3 \mathrm{fmol} / \mathrm{mg}$ protein in WKY $(n=4)$ and SHR $(n$ $=4)$, respectively.

Competition studies. The DA-1 antagonist SCH-23390 was more effective than its inactive isomer SCH-23388 in competing for specific ${ }^{125} \mathrm{I}-\mathrm{SCH}-23982$ binding sites, indicating stereoselectivity in both WKY and SHR (Fig. 2). SCH 23390 competed for specific ${ }^{125} \mathrm{I}-\mathrm{SCH}-23982$ binding sites to a similar extent in WKY and SHR. The $K_{\mathrm{i}}$ for SCH 23390 and SCH 23388 was $3.0 \pm 1.3$ and $41.3 \pm 1.1 \mathrm{nM}$, respectively, in WKY $(n$ $=4$ ) and 3.4 \pm 1.4 and $41.4 \pm 1.4 \mathrm{nM}$, respectively, in SHR. In contrast, $\mathrm{DA}_{1}$ agonists competed for specific ${ }^{125} \mathrm{I}-\mathrm{SCH} 23982$ binding sites more effectively in WKY than SHR. Three DA agonists (fenoldopam, SKF-38393, and SND-919-C12) had a lower binding affinity (higher $K_{\mathrm{i}}$ ) in SHR when compared to WKY (Table I, Fig. 2B, 1-3).

\section{$A C$ studies}

Effect of DA-1 agonists. Basal PCT AC activity was similar in WKY $(58.7 \pm 21.2 \mathrm{fmol} / 3 \mathrm{~mm} \mathrm{PCT} / 20 \mathrm{~min}, n=6)$ and SHR $(64.2 \pm 10.9, n=5)$. These values are similar to those reported by Morel and Doucet in the Wistar rat (32). The DA-1 agonist, fenoldopam (100 $\mathrm{nM}$ and $10 \mu \mathrm{M})$ increased $\mathrm{AC}$ activity in PCT of the WKY $(n=5)$. In contrast, in the PCT of SHR, fenoldopam (100 nM) had little effect on AC activity (Fig. 3). In a separate group of experiments, fenoldopam-stimulated AC activity in the PCT of WKY was blocked by the DA-1 antagonist, $\mathrm{SCH}-23390(n=6)$ but not by the beta adrenergic antagonist (-)-propranolol $(n=6)$ demonstrating specificity (Fig. 4). In this series of experiments a modest but significant increase over basal AC activity was measured in the SHR. The fenoldopam-stimulated-AC activity was not inhibited by SCH 23390. (-)-Propranolol significantly inhibited the fenoldo-

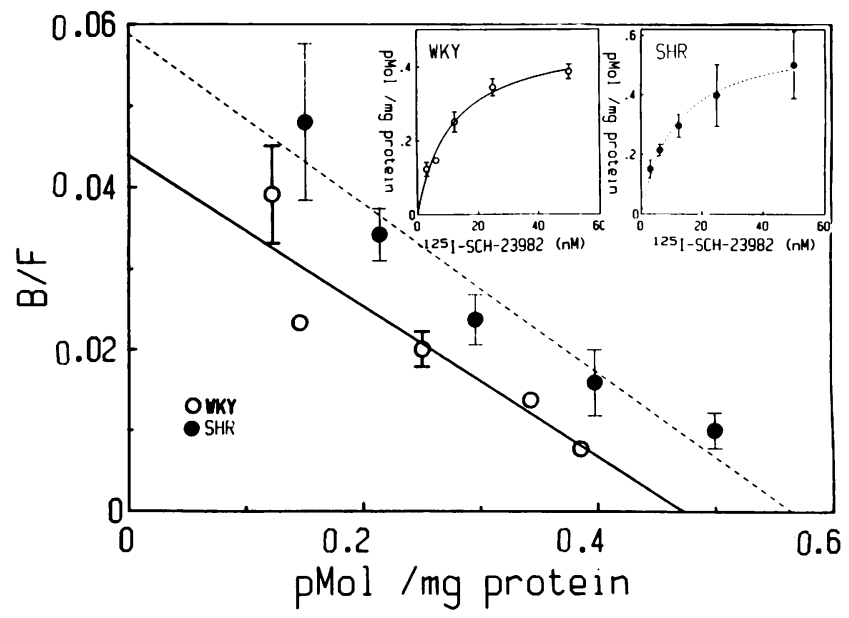

Figure 1. Scatchard plots of specific ${ }^{125} \mathrm{I}-\mathrm{SCH}-23982$ binding. Scatchard plots of ${ }^{125} \mathrm{I}-\mathrm{SCH}-23982$ binding to microdissected PCT from WKY and SHR $(n=4)$ showed no differences in affinity or receptor density. Nonspecific binding was measured using the selective DA-1 antagonist SCH-23390 $(10 \mu \mathrm{M})$. Data are mean $\pm \mathrm{SE}$ (error bars). No error bars are shown where SE is smaller than the symbols. Inset graphs show specific binding as a function of radioligand concentration.
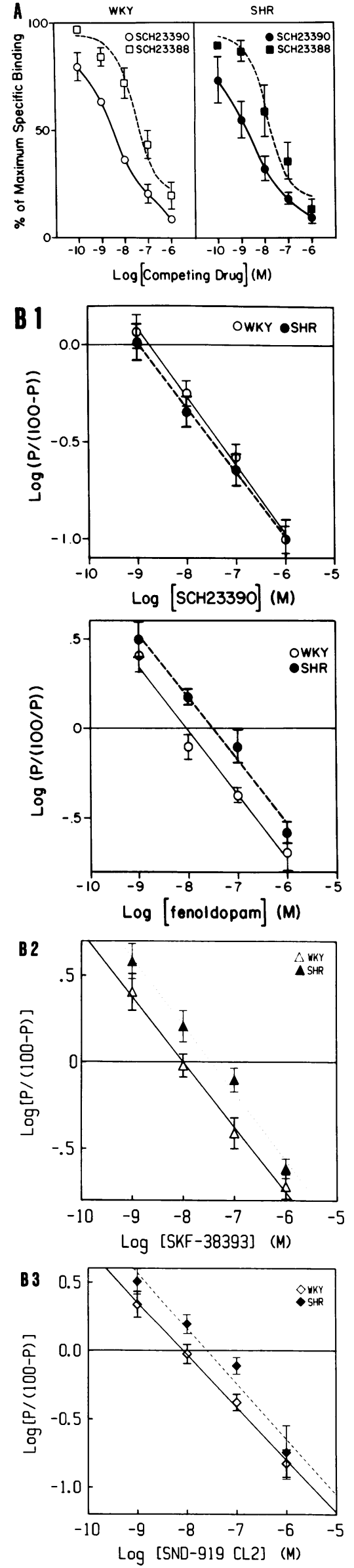

Figure 2. (A) Competition studies using DA-1 antagonist. SCH-23390 and its inactive isomer SCH-23388 showed similar stereoselective competition for specific ${ }^{125} \mathrm{I}-\mathrm{SCH}-23982(1 \mathrm{nM})$ binding in both the WKY and SHR PCT $(n=4)$. Data are mean \pm SE. (BI-3) Loglogit graphs of competition studies using DA-1 agonist (mean $\pm S E$ ). In contrast to studies using the DA-1 antagonist SCH 23390 (B1, top panel regraphed from $A$ ), the $K_{\mathrm{i}}$ values (Table I) of agonists (fenoldopam $[B 1$, bottom panel], SKF 38393 [B2], and SND-919$C 12[B 3])$ were greater in the SHR than the WKY. The numbers of experiments ranged from six to eight per drug. 
Table I. Inhibition Constants $\left(K_{i}, n M\right.$, mean $\left.\pm S E\right)$ Calculated from Competition Studies (Fig. 2)

\begin{tabular}{lccccc}
\hline & \multicolumn{2}{c}{ WKY } & & \multicolumn{2}{c}{ SHR } \\
\cline { 2 - 3 } \cline { 5 - 6 } DA-1 drugs & $K_{\mathrm{i}}$ & $n$ & & $K_{\mathrm{i}}$ & $n$ \\
\hline Agonists & & & & \\
$\quad$ SKF 38393 & $15.2 \pm 0.8$ & 8 & & $40.4 \pm 0.8^{*}$ & 6 \\
SND-919 C12 & $11.4 \pm 0.9$ & 7 & & $27.7 \pm 0.7^{*}$ & 6 \\
$\quad$ Fenoldopam & $12.4 \pm 3.1$ & 6 & $38.0 \pm 1.2^{*}$ & 7 \\
Antagonists & & & & \\
SCH 23390 & $3.0 \pm 1.3$ & 4 & $3.4 \pm 1.4$ & 4 \\
SCH 23388 & $41.3 \pm 1.1^{\ddagger}$ & 4 & $41.4 \pm 1.4^{\ddagger}$ & 4 \\
& & & & & \\
\hline
\end{tabular}

${ }^{*} P<0.05$ WKY vs. SHR.

${ }^{\ddagger} P<0.05$ SCH 23390 vs. SCH 23388.

pam-stimulated-AC activity in the SHR indicating a possible beta-receptor mediation of the AC response. Moreover, the $\mathrm{DA}_{1}$ agonist-stimulated-AC activity measured in the SHR was significantly lower than that measured in the WKY.

Since the DA-1 agonist, fenoldopam, demonstrated lower AC stimulation in the SHR when compared to the WKY, we examined the ability of other DA agonists to stimulate AC activity in the PCT of the SHR. The other DA-1 agonists, SKF-38393 and SND-919-C12, stimulated AC activity in WKY but not in SHR (Fig. 5).

Effect of forskolin and parathyroid hormone on AC activity. To determine whether the inability of DA-1 agonists to stimulate PCT AC activity in SHR was a generalized defect of the AC enzyme in the PCT, we studied other drugs (parathyroid hormone and forskolin), which are known to stimulate AC. Under the same experimental conditions forskolin and parathyroid hormone stimulated AC activity in PCT of WKY and SHR (Fig. 5) to a similar extent as that found by other investigators (33). Thus the DA-1 stimulated AC defect in the SHR may be selective to the DA-1 system.

Effect of guanine nucleotides on AC activity. To determine the influence of $\mathrm{G}$ proteins on DA-1-stimulated AC activity,

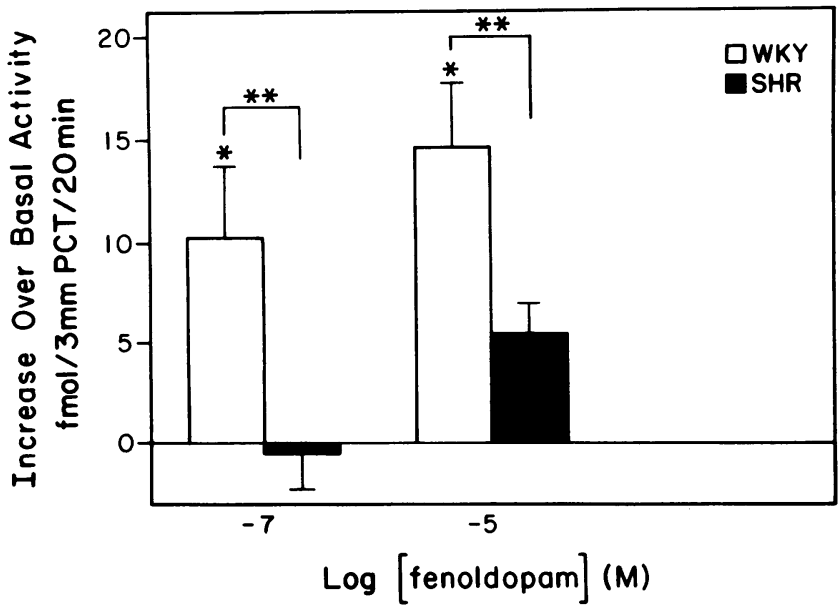

Figure 3. Effect of DA-1 agonist on AC activity in PCT (mean \pm SE). Fenoldopam (the selective DA-1 agonist) stimulated AC activity at two concentrations in the WKY but not in the SHR $(n=5) .{ }^{*} P$ $<0.05$ vs. basal activity in WKY $=64.2 \pm 13.4$ and SHR

$=52.3 \pm 11.4 \mathrm{fmol} / 3 \mathrm{~mm}$ PCT $/ 20 \mathrm{~min}^{* *} P<0.05 \mathrm{WKY}$ vs. SHR.

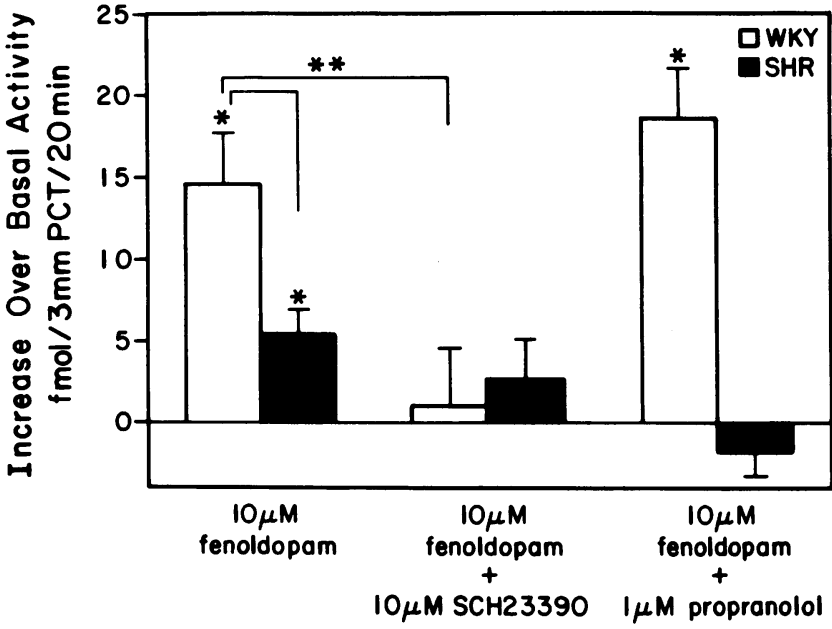

Figure 4. Effect of DA-1 agonist and antagonist on AC activity in PCT (mean \pm SE). In the WKY $(n=4)$, fenoldopam (selective DA-1 agonist)-stimulated AC activity was inhibited by SCH-23390 (selective DA-1 antagonist) but not (-)-propranolol (selective beta adrenergic antagonist). The modest stimulatory effect of fenoldopam on AC activity in the SHR $(n=4)$ was inhibited by $(-)$-propranolol but not by SCH-23390. ${ }^{*} P<0.05$ vs. basal activity; ${ }^{* *} P<0.05$ WKY vs. SHR; ${ }^{* *} P<0.05$ WKY fenoldopam alone vs. WKY fenoldopam $+\mathrm{SCH} 23390$.

the ability of either GTP or its nonhydrolyzable analogue $\mathrm{Gpp}(\mathrm{NH}) \mathrm{p}$ to stimulate AC activity in PCT was studied. Both GTP and Gpp(NH)p demonstrated a concentration-related increase in AC activity that was similar in the WKY and SHR (Fig. 6). The increase in AC activity elicited by $\mathrm{Gpp}(\mathrm{NH}) \mathrm{p}$ was greater than that found for GTP.

The ability of the selective DA-1 agonist, SND 919-C12, to stimulate AC activity was increased by both GTP and Gpp(NH)p in WKY similar to that reported for other $D_{1}$ receptors (34). In the SHR, however, SND failed to increase the stimulation of AC activity by either GTP or Gpp(NH)p (Fig. 7).

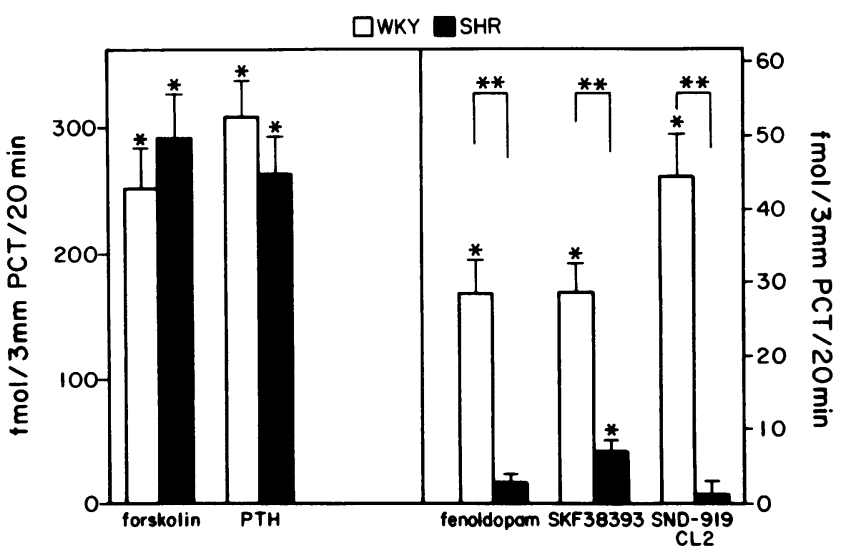

Figure 5. Effect of drugs on AC activity in PCT (mean \pm SE). There was no difference between the ability of forskolin $(10 \mu \mathrm{M})$ (which stimulates the Gs protein AC complex) and parathyroid hormone (1 $\mu \mathrm{M})$ to stimulate AC activity in the WKY $(n=4)$ and in the SHR $(n$ $=4)$. Three DA-1 agonists; fenoldopam (10 $\mu \mathrm{M})$, SKF-38393 (10 $\mu \mathrm{M})$, and SND-919-CL2 $(1 \mu \mathrm{M})$ showed a reduced AC stimulation in the SHR when compared to the WKY $(n=4) .{ }^{*} P<0.05$ from basal $(\mathrm{WKY}=79.6 \pm 12.5, \mathrm{SHR}=90.4 \pm 17.8 \mathrm{fmol} / 3 \mathrm{~mm} \mathrm{PCT} / 20 \mathrm{~min}, n$ $=4) ;{ }^{* *} P<0.05$ WKY vs. SHR. 

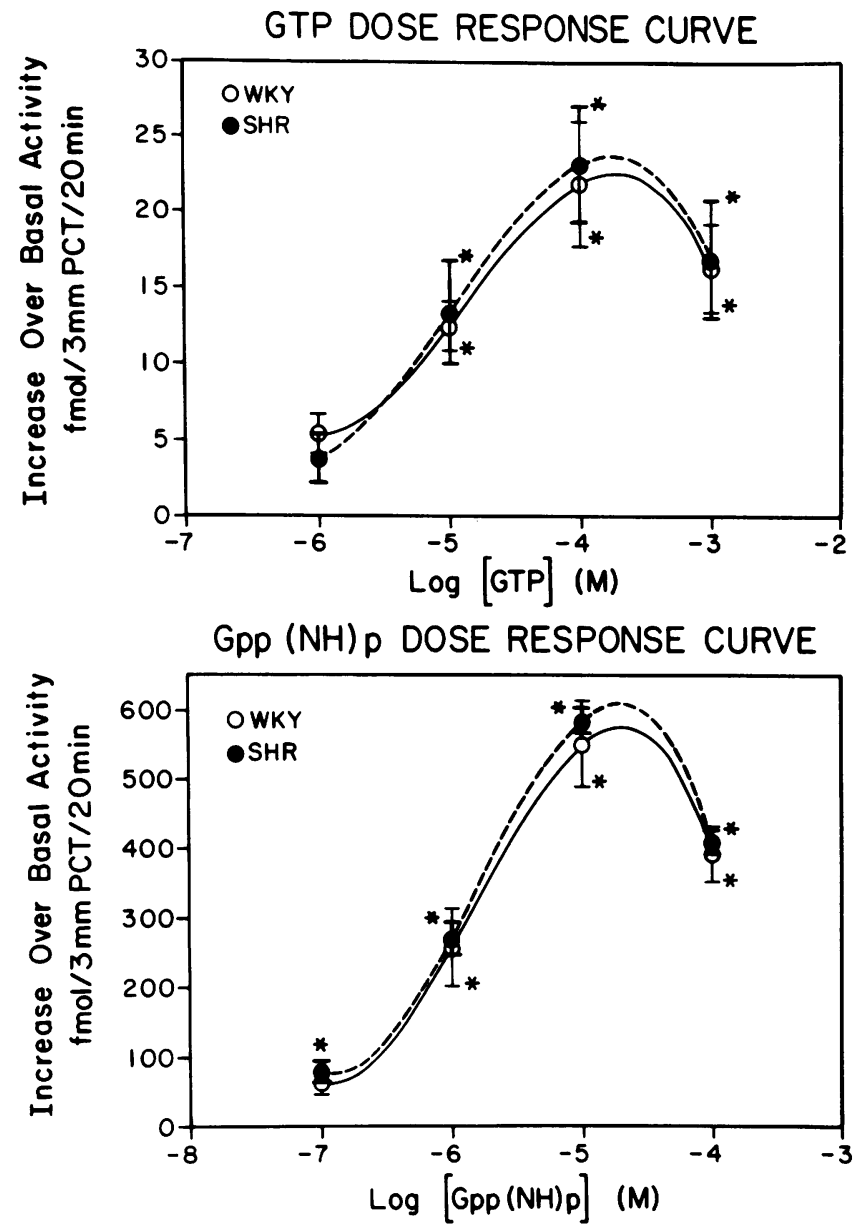

Figure 6. Effect of guanine nucleotides on AC activity in PCT (mean \pm SE). GTP and the nonhydrolyzable GTP analogue, Gpp(NH)p, stimulated AC activity to a similar extent in the WKY $(n=4)$ and the SHR $(n=4) .{ }^{*} P<0.05$ from basal (WKY $=34.2 \pm 6.5, \mathrm{SHR}=39.8 \pm 11.1 \mathrm{fmol} / 3 \mathrm{~mm} \mathrm{PCT} / 20 \mathrm{~min}, n=4)$.

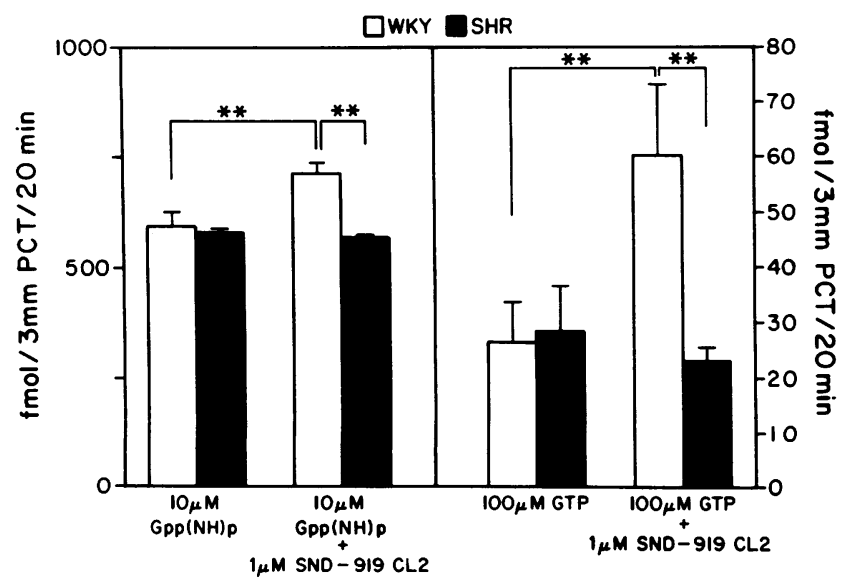

Figure 7. Effect of guanine nucleotides and DA-1 agonist on AC activity (increase over basal) in PCT (mean \pm SE). The DA-1 agonist, SND-919-CL2 increased the ability of Gpp(NH)p (left panel) and GTP (right panel) to stimulate AC activity in the WKY $(n=4)$, but not in the SHR $(n=4) .{ }^{* *} P<0.05$ GTP or Gpp(NH)p alone vs. GTP or Gpp(NH)p + SND; ${ }^{* *} P<0.05$ WKY vs. SHR.
Fenoldopam stimulated AC activity in the 3-wk-old WKY and $S H R$. To determine if the DA-1 AC coupling defect was present before the onset of hypertension, we measured fenoldopam stimulated AC activity in the PCT of 3-wk-old WKY and SHR (Table II). The DA-1 agonist stimulated AC activity in PCT of WKY as early as $3 \mathrm{wk}$ of age; the stimulatory effect was greater at 18-22 wk. In contrast, no such stimulatory effect was noted in SHR at either age group.

\section{Photoaffinity labeling of the DA-1 receptor}

Fig. 8, $A$ and $B$ shows the results obtained when kidney tubules and striatum were incubated with ${ }^{125} \mathrm{I}-\mathrm{MAB}$, photolyzed, and subjected to SDS-PAGE. Striatal tissue from the WKY was included as a control (Fig. $8 \mathrm{~B}$ ). Analysis of the migration distance of the labeled bands relative to proteins of known molecular weight showed that the photoaffinity probe was specifically incorporated into a diffuse polypeptide band of apparent molecular weight of 74,000 D in both the PCT and striatum. In the kidney two minor bands, with apparent molecular weights of 50,000 and 32,000 D were also present in the WKY. In the SHR only the 32,000-D band was discernable in the kidney. The striatum also demonstrated a 74,000-D band, whereas the smaller bands were 55,000 and $29,000 \mathrm{D}$, respectively. The incorporation of ${ }^{125} \mathrm{I}-\mathrm{MAB}$ was blocked by the DA-1 antagonist SCH-23390. The apparent molecular weight of the ${ }^{125}$ I-MAB binding sites obtained from solubilized PCT segments was similar in the WKY and SHR except that the 50,000-D band found in the WKY was absent or greatly reduced in intensity in the SHR when compared to the WKY (Fig. $8 \mathrm{~A}$ ).

\section{Discussion}

These studies show that the DA-1 agonists, fenoldopam, SKF-38393, and SND-919-C12 increase AC activity in the PCT of the WKY but not in the SHR despite similar DA-1 receptor density, affinity, and apparent molecular weight. This defect is selective since stimulation of AC activity in the PCT by other agents such as parathyroid hormone and forskolin are similar in WKY and SHR. Moreover, Guanyl nucleotides stimulated AC activity to a similar extent in WKY and SHR. Thus, these studies suggest that the decreased ability of DA-1 agonists to stimulate AC activity in the PCT of SHR is due to an altered DA-1 receptor-G protein coupling mechanisms. This is supported by the decreased ability of three different DA-1 agonists to compete for specific ${ }^{125}$ I-SCH 23982 binding sites in the SHR. An aberrant DA-1 receptor-mediated cou-

Table II. Effect of DA-1 Agonist, Fenoldopam (10 $\mu M)$ on AC Activity in PCT in 3-and 18-22-Wk-Old Rats

\begin{tabular}{lcc}
\hline \multicolumn{1}{c}{ Age } & Basal & Fenoldopam \\
\hline \multicolumn{1}{c}{$w k$} & & \\
3 WKY & $79.4 \pm 13.2$ & $95.8 \pm 17.0^{*}$ \\
3 SHR & $57.7 \pm 14.1$ & $58.8 \pm 11.0$ \\
$18-22$ WKY & $79.6 \pm 12.5$ & $149.1 \pm 15.9^{* \neq}$ \\
$18-22$ SHR & $90.4 \pm 17.8$ & $87.5 \pm 14.3$
\end{tabular}

All values are expressed as mean $\pm \mathrm{SEM}(\mathrm{pmol} / 3 \mathrm{~mm} \mathrm{PCT} / 20 \mathrm{~min})$, $n=3$.

${ }^{*} P<0.05$ compared to basal, paired $t$ test.

${ }^{\ddagger} P<0.05$ vs. 3 wk WKY, ANOVA, Scheffe's test. 

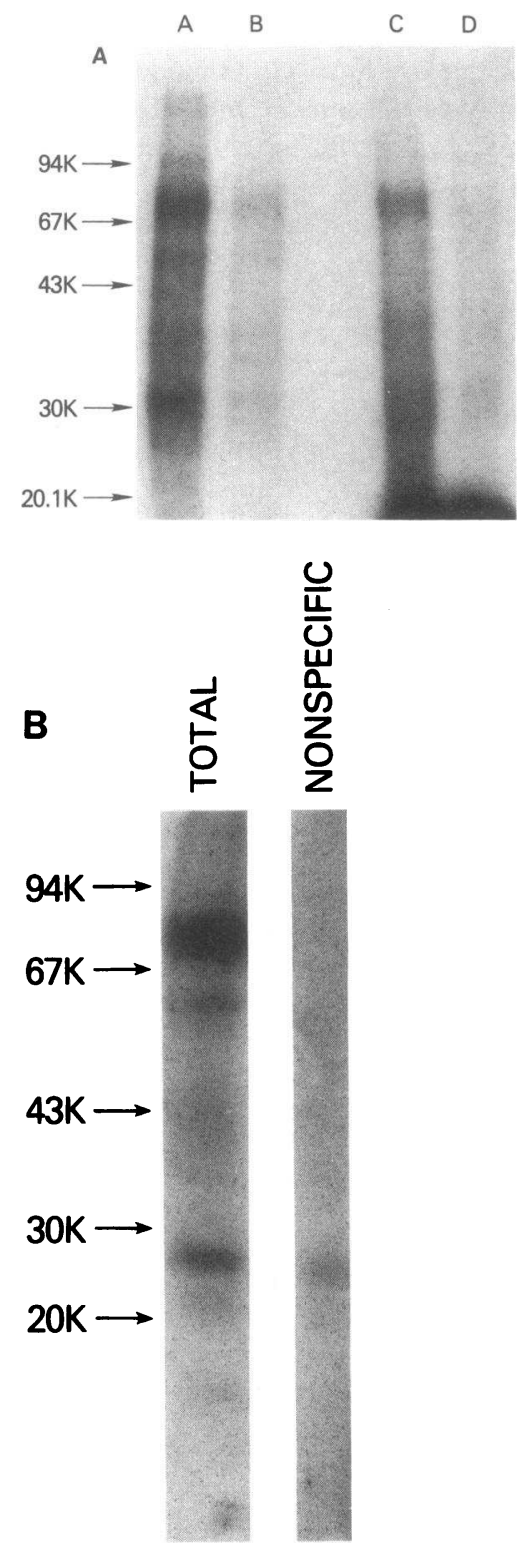

Figure 8. Photoaffinity labeling of DA-1 receptor with ${ }^{125} \mathrm{I}-\mathrm{MAB}$ in PCT from WKY and SHR $(A)$ and in the striatum of the WKY (B). PCT from WKY (lanes $A$ and $B$ ), SHR (lanes $C$ and $D$ ) and striatum (lanes labeled "Total" and "Nonspecific") were incubated with 375 pM ${ }^{125}$ I-MAB, in the absence (lanes $A$ $C$, and Total) or presence (lanes $B, D$ and Nonspecific) of $10 \mu \mathrm{M}$ SCH 23390. After incubation with the photoaffinity probe, the tissues were washed, photolyzed, and subjected to electrophoresis on $10 \%$ polyacrylamide gels, as described under Methods. Arrows represent the molecular weight of known proteins used as standards and shown $\times 1,000(\mathrm{~K})$. The photoaffinity probe was specifically incorporated into a diffuse polypeptide band of apparent molecular weight of $74,000 \mathrm{D}$. In addition, two minor bands, with apparent molecular weights of 50,000 and $32,000 \mathrm{D}$ were also present in the PCT. The 50,000-D band was not as apparent in the SHR compared to the WKY.

The incorporation of ${ }^{125} \mathrm{I}-\mathrm{MAB}$ into these three bands was blocked by the DA-1 antagonist SCH-23390. The apparent molecular weight of the ${ }^{125} \mathrm{I}-\mathrm{MAB}$ binding sites obtained from solubilized PCT segments was similar between the WKY and SHR but differed from the 29,000 band found in the striatum.

pling mechanism is supported also by the failure of the guanyl nucleotides, GTP and Gpp(NH)p, to enhance DA-1-mediated AC activity.

The proposed DA-1 defect may not be related to gross abnormalities in the DA-1 receptor, since the molecular weight of the solubilized receptor is similar in the SHR and WKY. The high affinity $\left(K_{\mathrm{d}}=220 \mathrm{pM}\right) \mathrm{D}-1$ receptor photoaffinity probe, ${ }^{125} \mathrm{I}-\mathrm{MAB}(31)$, was used to label a PCT dopamine binding site. ${ }^{125}$ I-MAB binding of the striatum of the WKY was included as a control. The apparent molecular weight of the major WKY and SHR PCT ${ }^{125}$ I-MAB binding site is similar to the central nervous system D- 1 receptor found in bovine, canine, and porcine striatum $(74,000 \mathrm{D})(31)$. The smaller subunit of 50,000 D found in the PCT also has a similar molecular weight to a subunit found in the striatum $(55,000 \mathrm{D})$.
There appears to be a reduction in the quantity of the 50,000D subunit in the SHR when compared to the WKY. The significance of the 50,000-D subunit needs to be determined in future studies.

The 32,000-D subunit is unique to the PCT. Whether this represents a fundamental difference in the DA-1 receptor as compared to the central nervous system D- 1 receptor or whether the 32,000-D subunit is a fragment of the 74,000-D subunit will have to be determined. This first demonstration of similar molecular weights between the central D-1 receptor and the peripheral DA-1 receptor is in concordance with other similarities of the central and peripheral dopamine receptors such as activation of $\mathrm{AC}$ through the Gs protein and a similar pharmacologic profile (29).

Uncoupling defects exist for other cell membrane receptor systems coupled to AC stimulation. There is a striking similarity between the DA-1 defect described in the present study and the uncoupling of beta adrenergic receptors with $\mathrm{AC}$ in mouse S49 lymphoma cells described by Haga et al. (33). In both cases there was failure of agonist-stimulated AC activity, guanyl nucleotide enhancement of agonist-stimulated AC activity, and reduced agonist affinity for the receptor. These defects have been found in the face of normal antagonist binding to the receptor. There are other examples of receptor AC uncoupling in pathologic states. For example, patients with pseudohypoparathyroidism can be subgrouped into categories based on the site of deficiency in the parathyroid hormone AC coupling (i.e., PTH hormone defect, pseudopseudohypoparathyroidism: Gs protein defect, pseudohypoparathyroidism type Ia). Some patients, however, present with normal parathyroid hormone receptors, Gs proteins, and $\mathrm{AC}$ activation through the Gs protein, yet demonstrate a gentically inherited receptor-AC coupling not unlike the DA-1 defect found in the present study (pseudohypoparathyroidism type Ib) (35). Similarly, insulin resistance in denervated rat skeletal muscle is a result of a post receptor coupling defect (36). As another example, addition of phospholipase $C$ to plasma membranes from rat liver was associated with a loss of glucagon-stimulated AC activity and reduced agonist binding affinity compared with untreated membranes (37). These experiments suggested that the phospholipid microenvironment surrounding each receptor may influence agonist but not antagonist binding.

Abnormalities in the renal dopaminergic system have been reported in some animal models of hypertension $(6,21-26$, $38-40$ ). In young SHR where some have reported that renal tissue or urinary concentrations of DA are elevated $(21,23$, 24), sodium excretion is less in the young SHR than its normotensive WKY control $(23,41)$. Inhibition of peripheral dopamine production by carbidopa decreased sodium excretion and accelerated the development of hypertension in the SHR (24). In the Dahl salt-sensitive rat, a decreased renal dopamine production is associated with a lesser sodium excretion than the Dahl salt-resistant rat (39). Thus, aberrant renal DA concentrations and/or release can be found in experimental models of hypertension. Studies from our laboratory $(6,26)$ and others (25) have demonstrated possible physiologic consequences of an aberrant PCT DA-1 receptor in the SHR. The intrarenal arterial infusion of the DA-1 agonist, SKF 38392 results in a diuresis and natriuresis in WKY but not SHR (26). There may also be a decreased natriuretic effect of endogenous dopamine in SHR since the intrarenal arterial infusion of the 
DA-1 antagonist SCH 23390 decreased sodium excretion in WKY but not SHR (6). Whether the aberrant DA concentrations and/or release are compensatory mechanisms to overcome a defective proximal tubular DA-1 receptor-coupling remains to be determined. The possibility that the DA-1 AC coupling is a primary defect is supported by our studies that demonstrate that the DA-1 AC coupling defect is found in the 3-wk-old SHR and persists with the establishment of hypertension.

The existence of DA-1 AC coupling defect has yet to be reported in human essential hypertension. However, there are evidences for a decreased renal action of DA-1 agonists in hypertensive subjects. A decreased natriuretic and renal vasodilator effect of DA-1 agonists has been described in some hypertensive patients (42-45). The natriuretic effect of fenoldopam (100 mg per os) measured by Carey et al. (43) was blunted in hypertensive patients when compared to normotensive subjects studied by Stote et al. (46) under similar experimental conditions. Defects in the renal dopaminergic system may be an inherited disorder. Some normotensive subjects with family history of hypertension have high urinary dopamine and lower sodium excretion compared with those without a family history of hypertension (45).

The precise physiological consequence of an apparent DA-1 receptor-AC defect in the PCT, either permanent or temporary, remains to be determined. Although an increased sodium reabsorption in the superficial proximal tubule of SHR has not been reported (47), other nephrons or nephron segments may be involved (48). Lithium clearance studies have revealed increased reabsorption of sodium in proximal tubules of conscious SHR (48). The $\mathrm{Na}^{+} / \mathrm{H}^{+}$antiport activity in renal brush border membrane vesicles in SHR is apparently increased (49). This is a possible site of expression of the DA-1-AC coupling defect in SHR, since AC may mediate the inhibitory effect of DA on this antiporter in WKY (14). Whether the tendency for sodium retention in SHR that is aggravated when DA production is decreased (24) is due solely to this proximal tubular DA-1-AC defect remains to be determined. $\mathrm{Na}^{+} / \mathrm{K}^{+}$ATPase activity is also increased in the proximal tubule of the young SHR (50). The role of deeper or more distal segments of the nephron where dopamine receptors (17, 19) and effects $(15,16,20)$ have been also demonstrated remains to be determined. However, there are reports of increased sodium transport in the proximal tubule of other genetic models of hypertension $(51,52)$. In the Dahl salt-sensitive rat, we have found (Kinoshita, S., and R. A. Felder, unpublished observations) that a DA-1 receptor-AC coupling defect is also present in the PCT of this strain. Bertorello and Aperia have reported that DA increased $\mathrm{Na}^{+} / \mathrm{K}^{+} \mathrm{ATPase}$ activity in PCT of Dahl salt-sensitive rat but had the opposite and expected effect in Dahl salt-resistant rat (40). Dopamine may also decrease proximal sodium transport by inhibiting $\mathrm{Na}^{+} / \mathrm{K}^{+} \mathrm{ATPase}$ activity $(1,5,11-13)$. Thus, it is possible that the DA-1 receptor defect in the SHR and Dahl salt-sensitive rat may play a role in the altered renal sodium transport in these models of hypertension.

In summary, we have shown that DA-1 receptor or G protein coupling is defective in the PCT of the SHR. This may represent an in vivo model of an uncoupled cell surface receptor that may contribute to the pathophysiology of hypertension in the SHR.

\section{Acknowledgments}

The authors would like to thank Pedro A. Jose and Robert M. Carey for their suggestions and critiques.

This paper was supported in part by grants DK39308 and HL33498 from the National Institutes of Health.

\section{References}

1. Seri, I., B. C. Kone, S. R. Gullans, A. Aperia, B. M. Brenner, and B. J. Ballermann. 1988. Locally formed dopamine inhibits $\mathrm{Na}^{+}-\mathrm{K}^{+}-$ ATPase activity in rat renal cortical tubule cells. Am. J. Physiol. 255:F666-F673.

2. Jeffrey, R. F., T. M. MacDonald, J. Brown, P. W. H. Rae, and M. R. Lee. 1988. The effect of lithium on the renal response to the dopamine prodrug gludopa in normal man. Br. J. Clin. Pharmacol. 25:725-732.

3. Hansell, P., N.-E. Ande'n, M. Grabowska-Ande'n, and H. R. Ulfendahl. 1988. Atrial natriuretic factor, urinary catechol compounds and electrolyte excretion in rats during normal hydration and isotonic volume expansion. Influence of dopamine receptor blockade. Acta Physiol. Scand. 134:421-428.

4. Richet, G., F. Wahbe, J. Hagege, and W. Wiemeyer. 1987. Extraneuronal production of dopamine by kidney slices in normo and hypertensive rats. Clin. Exp. Hypertens. A9(Suppl.1):127-134.

5. Bertorello, A., T. Hokfelt, M. Goldstein, and A. Aperia. 1988. Proximal tubule $\mathrm{Na}^{+}-\mathrm{K}^{+}$-ATPase activity is inhibited during high-salt diet: evidence for DA-mediated effect. Am. J. Physiol. 254 (Renal Fluid Electrolyte Physiol. 23):F795-F801.

6. Jose, P. A., P. Cody, and G. M. Eisner. 1989. Endogenous dopamine (DA) regulates renal sodium transport in normotensive but not hypertensive rat. Kidney Int. 35:328 (Abstract).

7. Jose, P. A., R. A. Felder, R. R. Holloway, and G. M. Eisner. 1986. Dopamine receptors modulate sodium excretion in denervated kidney. Am. J. Physiol. 250 (Renal Fluid Electrolyte Physiol. 19): F1033-F1038.

8. Pelayo, J. C., R. D. Fildes, G. M. Eisner, and P. A. Jose. 1983. Effects of dopamine blockade on renal sodium excretion. Am. J. Physiol. 245 (Renal Fluid Electrolyte Physiol. 14):F247-F253.

8a. Siragy, H. M., R. A. Felder, N. L. Howell, R. L. Chevalier, M. J. Peach, and R. M. Carey. 1989. Evidence that intrarenal dopamine acts as a paracrine substance at the renal tubule. Am. J. Physiol. 257 (Renal, Fluid, Electrolyte Physiol. 3):F469-F477.

9. Srinivasan, K., and J. Awapara. 1978. Substrate specificity and other properties of dopa decarboxylase from guinea pig kidneys. Biochim. Biophys. Acta. 526:597-604.

10. Hagege, J., and G. Richet. 1985. Proximal tubule dopamine histofluorescence in renal slices incubated with L-dopa. Kidney Int. 27:3-8.

11. Seri, I., B. C. Kone, S. R. Gullans, B. M. Brenner, and B. J. Ballermann. 1989. Inhibition of Na-K-ATPase (Na-K) in rat renal cortical tubule cells (RCTC) by locally formed DA (DA) involves $\mathrm{DA}_{1}$ but not $\mathrm{DA}_{2}$, receptors. Kidney Int. 35:320. (Abstr.)

12. Bertorello, A., and A. Aperia. 1988. Both $\mathrm{DA}_{1}$ and $\mathrm{DA}_{2}$ receptor agonists are necessary to inhibit NaKATPase activity in proximal tubules from rat kidney. Acta Physiol. Scand. 132:441-443.

13. Bertorello, A., and A. Aperia. 1989. $\mathrm{Na}^{+}-\mathrm{K}^{+}-\mathrm{ATPase}$ in an effector protein for protein kinase $\mathrm{C}$ in renal proximal tubule cells. $\mathrm{Am}$. J. Physiol. 254 (Renal Fluids Electrolyte Physiol. 25):F370-F373.

14. Felder, C. C., T. Campbell, and P. A. Jose. 1989. Role of cAMP on dopamine-1 (DA-1) receptor regulated $\mathrm{Na}^{+}-\mathrm{H}^{+}$antiport in renal tubular brush border membrane vesicles (BBMV). Kidney Int. 35:172. (Abstr.)

15. Hughes, J. M., N. V. Ragsdale, R. A. Felder, R. L. Chevalier, B. King, and R. M. Carey. 1988. Diuresis and natriuresis during continuous dopamine-1 receptor stimulation. Hypertension. 11 (Suppl. I):I-69-I-74. 
16. Muto, S., K. Tabei, Y. Asano, and M. Imai. 1985. Dopaminergic inhibition of the action of vasopressin on the cortical collecting tubule. Eur. J. Pharmacol. 114:393-397.

17. Felder, R. A., M. Blecher, P. L. Calcagno, and P. A. Jose. 1984. Dopamine receptors in the proximal tubule of the rabbit. Am J. Physiol. 247 (Renal Fluid Electrolyte Physiol. 16):F499-F505.

18. Kinoshita, S., and R. A. Felder. 1989. Dopamine-1 receptors in the rat proximal convoluted tubule: Autoradiographic and adenylate cyclase studies. Am J. Physiol. In press.

19. Felder, R. A., C. C. Felder, G. M. Eisner, and P. A. Jose. 1989. The dopamine receptor in the adult and maturing kidney. Am. J. Physiol. In press.

20. Bello-Reuss, E., Y. Higashi, and Y. Kaneda. 1982. Dopamine decreases fluid reabsorption in straight portions of rabbit proximal tubule. Am. J. Physiol. 242 (Fluid Electrolyte Physiol. 11):F634-F640.

21. Racz, K., O. Kuchel, N. T. Buu, and S. Tenneson. 1986. Peripheral dopamine synthesis and metabolism in spontaneously hypertensive rats. Cir. Res. 58:889-897.

22. Kuchel, O., K. Racz, W. Debinski, P. Falardeau, and N. T. Buu. 1987. Contrasting dopaminergic patterns in two forms of genetic hypertension. Clin. Exp. Hypertens. A9:987-1008.

23. Kambara, S., M. Yoshimura, H. Takahashi, and H. Ijichi. 1987. Enhanced synthesis of renal dopamine and impaired natriuresis in spontaneously hypertensive rats (SHRs). Jpn. Heart J. 28:594. (Abst.)

24. Yoshimura, M., S. Kambara, H. Okabayashi, I. Ikegaiki, M. Matsuzawa, K. Suga, H. Takahashi, and H. Ijichi. 1987. Pathophysiological role of dopamine on the development of hypertension in rats. Jpn. Circ. J. 51:1226-1231.

25. Weinstock, J., J. W. Wilson, D. Ladd, M. Brenner, D. M. Ackerman, A. L. Blumberg, R. A. Hahn, J. P. Hieble, H. M. Saurau, and V. D. Wiebelhaus. 1983. Dopaminergic benzazepines with divergent cardiovascular profiles. In Dopamine Receptors. C. Kaiser, and J. W. Kebabian, editors. Am. Chem. Soc., Wash. DC. 157-169.

26. Felder, R. A., M. G. Seikaly, G. M. Eisner, and P. A. Jose. 1988. Renal dopamine-1 defect in spontaneous hypertension. Contrib. Nephrol. 67:71-74.

27. Schmidt, U., and M. Horster. 1978. Sodium-potassium-activated adenosine triphosphatase: Methodology for quantification in microdissected renal tubule segments from freeze-dried and fresh tissue. In Methods in Pharmacology. M. Martinez-Maldonado, editor. Plenum Press, New York. Vol. 4B. 259-296.

28. Lowry, O. H., N. S. Rosebrough, A. L. Farr, and R. J. Randall. 1951. Protein measurement with Folin phenol reagent. J. Biol. Chem. 193:265-268.

29. Felder, R. A., and P. A. Jose. 1988. Dopamine receptors in rat kidneys identified with ${ }^{1.25} \mathrm{I}-\mathrm{SCH}$ 23982. Am. J. Physiol. 255 (Renal Fluid Electrolyte Physiol. 24):F970-F976.

30. Setler, P. E., H. M. Sarau, C. L. Zirkle, and H. L. Saunders. 1978. The central effects of a novel dopamine agonist. Eur. J. Pharmacol. 50:419-430.

31. Niznik, H. B., K. R. Jarvie, N. H. Bzowej, P. Seeman, R. K. Garlick, J. J. Miller, N. Baindur, and J. L. Neumeyer. 1988. Photoaffinity labeling of dopamine D1 receptors. Biochemistry 27:7594-7599.

32. Morel, F., and A. Doucet. 1986. Hormonal control of kidney functions at the cell level. Physiol. Rev. 66:377-468.

33. Haga, T., E. M. Ross, H. J. Anderson, and A. G. Gilman. 1977. Adenylate cyclase permanently uncoupled from hormone receptors in a novel variant of $\mathrm{S} 49$ mouse lymphoma cells. Proc. Natl. Acad. Sci. USA. 74:2016-2020.

34. Hess, E. J., and I. Creese. 1987. Biochemical characterization of dopamine receptors. In Dopamine Receptors. I. Creese, and C. M. Fraser, editors. Alan R. Liss, Inc., New York. 1-27.
35. Spiegel, A. M., M. A. Levine, G. D. Aurbach, R. W. Downs, Jr., S. J. Marx, R. D. Lasker, A. M. Moses, and N. A. Breslau. 1982. Deficiency of hormone receptor-adenylate cyclase coupling protein: basis for hormone resistance in pseudohypoparathyroidism. Am. J. Physiol. 243:E37-E42.

36. Burant, C. F., S. K. Lemmon, M. K. Treutelaar, and M. G. Buse. 1984. Insulin resistance of denervated rat muscle: a model for impaired receptor-function coupling. Am J. Physiol. 247:E657-E666.

37. Rubalcava, B., and M. Rodbell. 1973. The role of acidic phospholipids in glucagon action on rat liver adenylate cyclase. J. Biol. Chem. 248:3831-3837.

38. Fernandez-Pardal, J., and J. M. Saavedra. 1982. Catecholamines in discrete kidney regions. Changes in salt-sensitive Dahl hypertensive rats. Hypertension. 4:821-826.

39. Racz, K., O. Kuchel, and N. T. Buu. 1987. Abnormal adrenal catecholamine synthesis in salt-sensitive Dahl rats. Hypertension. 9:76-80.

40. Bertorello, A., M. L. Melzi, U. Ekblad, and A. Aperia. 1989. Alterations in renal Na,K-ATPase activity and affinity induced by high salt diet in the Dahl salt sensitive (SS) rats. Kidney Int. 35:323 (Abstr.)

41. Dilley, J. R., C. T. Stier, Jr., and W. Arendshorst. 1984. Abnormalities in glomerular function in rats developing spontaneous hypertension. Am. J. Physiol. 246 (Renal Fluid Electrolyte Physiol. 15):F12-F20.

42. Kikuchi, K., O. Iimura, I. Yamaji, S. Shibata, M. Nishimura, K. Aoki, A. Nozawa, T. Hasegawa, C. Honma, H. Kobayakawa, and H. Komura. 1987. The pathophysiological role of water-sodium balance and renal dopaminergic activity in overweight patients with essential hypertension. J. Clin. Hypertens. 3:3-11.

43. Carey, R. M., R. M. Stote, J. W. Dubb, L. H. Townsend, C. E. Rose, Jr., and D. L. Kaiser. 1984. Selective peripheral dopamine-1 receptor stimulation with fenoldopam in human essential hypertension. J. Clin. Invest. 74:2198-2207.

44. Nadler, J., S. Bughi, L. Ehrlich, and R. Horton. 1988. The effect of fenoldopam, a dopamine, agonist, on renal blood flow and prostacyclin release in normal and hypertensive man. Clin. Res. 36:571a. (Abstr.)

45. Saito, I., E. Takeshita, T. Saruta, S. Nagano, and T. Sekihara. 1986. Urinary dopamine excretion in normotensive subjects with or without family history of hypertension. J. Hypertens. 4:57-60.

46. Stote, R. M., J. W. Dubb, R. G. Familiar, B. B. Erb, and F. Alexander. 1983. A new oral renal vasodilator, fenoldopam. Clin. Pharmacol. Ther. 34:309-315.

47. DiBona, G. F., and L. L. Rios. 1978. Mechanism of exaggerated diuresis in spontaneously hypertensive rats. Am. J. Physiol. 235 (Renal Fluid Electrolyte Physiol. 4):F409-F416.

48. Biollaz, J., B. Waeber, J. Diezi, M. Burnier, and H. R. Brunner. 1986. Lithium infusion to study sodium handling in unanesthetized hypertensive rats. Hypertension. 8:117-121.

49. Shiekhamad, D., O. D. Jo, N. Yanagawa, and D. B. N. Lee. 1987. Sodium (Na) transport by isolated renal brush border membrane vesicles (BBMV) from spontaneously hypertensive rats (SHR): in creased $\mathrm{Na} / \mathrm{H}$ countertransport (CT). Kidney Int. 31:309 (Abstr.)

50. Garg, L. C., N. Narang, and S. McCardle. 1985. Na-K-ATPase in nephron segments of rat developing spontaneous hypertension. Am. J. Physiol. 249 (Renal Fluid Electrolyte Physiol. 18):F863-F869.

51. Parenti, P., G. M. Hanozet, and G. Bianchi. 1986. Sodium and glucose transport across brush border membranes from Milan hypertensive rats. Hypertension. 8:932-939.

52. Roos, J. C., K. A. Kirchner, J. D. Abernathy, and H. G. Langford. 1984. Differential effect of salt loading on sodium and lithium excretion in Dahl salt-resistant and -sensitive rats. Hypertension. $6: 420-424$ 